\title{
Community Safety Maps for Children in Japan: An Analysis from a Situational Crime Prevention Perspective
}

\author{
Nobuo Komiya
}

Received: 5 September 2011 / Accepted: 8 September 2011 /

Published online: 22 September 2011

(C) The Author(s) 2011. This article is published with open access at Springerlink.com

\begin{abstract}
Recent years have witnessed several major crimes against children both inside, and in the vicinity of, schools in Japan. These criminal incidents have heightened parental and community concerns regarding the safety of children in school. From the perspective of situational crime prevention, this study attempts to examine the nature and characteristics of community safety maps designed for children. It assesses the potential benefits of these maps and analyzes the structural and cultural obstacles for their implementation. This paper calls for more research into further innovative crime prevention strategies that can be used in Japanese schools so as to prevent children from becoming victims of crimes.
\end{abstract}

Keywords Community $\cdot$ Map $\cdot$ Crime opportunity $\cdot$ Risk prediction $\cdot$ Education $\cdot$ Child safety

\section{Introduction}

Japan has experienced a series of major crimes against children in the past decade. For example, there was a murder of eight children by a stranger in an elementary school in 2001 (Mainichi Newspapers, 27 November 2001). Between 2004 and 2005, four cases occurred in which elementary school children were abducted on their way home from school and subsequently murdered (Yomiuri Shimbun, 1 April 2004; The Nikkei, 10 December 2005). These criminal incidents against children heightened public concerns regarding child safety and parental anxiety regarding victimization of their children. In a public opinion survey conducted by the Japanese Cabinet Office (2006) following these criminal events, more than $70 \%$ of respondents expressed increased anxiety about their children being the victims of crime.

It is within this context of the increased victimization of school children and fear of crime among parents and the general public that this paper attempts to examine a recently developed crime prevention mechanism - community safety maps for children. The aims of this paper are to describe the nature and characteristics of community safety maps, explain

N. Komiya $(\bowtie)$

Department of Sociology, Rissho University, 4-2-16 Osaki, Shinagawa, Tokyo 141-8602, Japan e-mail: komiya@ris.ac.jp 
the potential benefits of these maps from the situational crime prevention perspective, and analyze major structural and cultural obstacles that may prevent them from being implemented.

\section{Situational Crime Prevention as an Analytical Framework}

The development of situational crime prevention is associated closely with the work of the British Government's criminological research department in the late 1970s and early 1980s, particularly that of Ronald Clarke (Crawford 1998: 66). Clarke (1997: 4) proffers the following definition of situational crime prevention:

Situational prevention comprises opportunity-reducing measures that (1) are directed at highly specific forms of crime, (2) involve the management, design or manipulation of the immediate environment in as systematic and permanent ways as possible, and (3) make crime more difficult and risky, or less rewarding and excusable as judged by a wide range of offenders.

The key word here is "opportunity." This theory argues that because opportunities play a role in causing all crime, crime can be prevented by reducing opportunities (Felson and Clarke 1998). Opportunity-focused criminology shares similar assumptions about the criminal offender and the criminal event with other theories such as rational choice theory (Cornish and Clarke 1986), routine activity theory (Cohen and Felson 1979; Felson 1998), crime pattern theory (Brantingham and Brantingham 1984), defensible space (Newman 1996), crime prevention through environmental design (Jeffery 1971; Crowe 2000), and broken windows theory (Wilson and Kelling 1982; Kelling and Coles 1996). In essence, all of these theories focus on identifying situational or spatial conditions with a high probability of crime occurrence, and not on identifying the motivated offenders.

Cornish and Clarke (2003: 90) present the latest evolution of the situational crime prevention framework by describing five sets (i.e., increase effort, increase risk, reduce reward, reduce provocation and remove excuse) of 25 techniques aimed at reducing the opportunities for crime. Among these techniques, Japan's community safety maps are based mainly on "access control" in the category of "increase effort" and "surveillance" in the category of "increase risk." Crime prevention through environmental design, which has significantly influenced the development of situational crime prevention (Clarke 1997: 7), is also composed chiefly of these two techniques (Crowe 2000: 36-8).

Crime opportunities are concentrated in space (Felson and Clarke 1998: 14). Thus, crime is concentrated strongly on small geographic units, commonly termed "hot spots" (Sherman et al. 1989; Weisburd and Mazerolle 2000). Recent research has shown that police efforts focused on "hot spots" can result in meaningful reductions in crime (Braga and Bond 2008). In essence, opportunity-blocking tactics at hot-spot locations may have a great effect on crime (Eck 2002). That is why Japan's community safety maps focus on "potential" hot spots of crime.

\section{Crime Prevention Programs in Japan}

Japan is well known for its low crime rates and close-knit community. Its informal social control is pervasive and based primarily on group orientation (Komiya 1999). As Japanese have obtained a sense of security by integrating themselves with groups, they had no choice 
but to strictly adhere to countless rules for group cohesiveness. In this process, the Japanese have become a patient and orderly people, and have successfully elevated their level of selfcontrol.

Less is known, however, about the ways the Japanese supervise their children, particularly before and after school. Unlike in Western countries, it is not customary for Japanese parents to pick up and drop off their children before and after school. There are also no school buses in operation. It is rather common for Japanese parents to leave their children at home by themselves or have them wait by themselves in the car. It is not a crime of child neglect in Japan to leave under age children unsupervised even though the number of monthly accidents resulting from young children being locked inside a car exceeds 200 (The Nikkei, 16 April 2010). Children who walk alone on the streets are more likely to become victims of a crime. For example, in 2008, the Japanese National Police Agency recorded that, of the elementary school children who were victimized, approximately 8,000 crimes occurred in parking lots, approximately 4,000 took place on the streets, and approximately 2,000 happened in parks. According to the 2006 Crime Victimization Survey of elementary school children conducted in Kobe by the Japanese National Police Agency, the victimization rate of street crimes was $14 \%$.

It is estimated that the majority of these crimes occur when the child victim is alone. This can be surmised from the number of cases reported to the Chiba Prefectural Police in 2009 in which children were the victims of crime, out of which $73 \%$ involved the victimization of children who were by themselves. Furthermore, an analysis on child kidnapping cases released by the Japanese National Police Agency in 2003 indicates that $69 \%$ of the cases involved targeting children who were alone.

To address this issue, two major crime prevention programs have been developed in recent years. They involved the use of a crime prevention buzzer as means of self-defense and the identification of fushinsya (persons plotting a crime). The major purpose and characteristics of these programs are described below.

\section{The Crime Prevention Buzzer}

The crime prevention buzzer is a simple electronic device that children would carry when they go about their daily routines. When children perceive themselves to be in physical danger of a possible criminal attack, they may press the buzzer and the sound of the buzzer may alert those around them. The purpose of the crime prevention buzzer is to deter criminal activity and defend oneself against criminals.

In Tokyo, the distribution of the crime prevention buzzer to elementary school students in the Shibuya and Katsushika Wards began in 2001, with the Suginami and Shinagawa Wards following suit in 2003. According to a survey conducted by the Japanese Ministry of Education, Culture, Sports, Science and Technology, in 2007, crime prevention buzzers had been handed out at $88 \%$ of elementary schools across the country.

Despite its popularity, there are several practical limitations that may prevent this device from achieving its intended crime prevention purposes. First, children who are tricked into following a criminal may not think of sounding their buzzers. A breakdown of child kidnapping cases disclosed by the Japanese National Police Agency in 2003 shows that 55\% of such cases involved the child being tricked into following the perpetrator voluntarily.

Second, children who are subjected to an attack may be so distressed that they are not capable of sounding their crime prevention buzzers. Furthermore, even if they have the presence of mind to sound their buzzers, there is the possibility that they do not work due to 
a non-functioning battery or a mechanical failure. A survey conducted by the National Consumer Affairs Center of Japan in 2008 found that $81 \%$ of local government entities that had distributed crime prevention buzzers had received complaints of malfunction.

Third, even if children are able to sound their buzzers, there is no guarantee that an adult will be in the vicinity to hear the alarm. Additionally, even if an adult is in the area, they may not be able to hear the alarm due to noise generated by common activities, such as passing automobiles and construction. Furthermore, there is also the possibility that even if someone hears the alarm, they will not come to the child's aid because they believe that it may be a prank. A story in a local newspaper contained the following account:

When messing around with my friends on the walk home from school, I accidently sounded the crime prevention buzzer that I had attached to my bag. The loud ringing sound that followed made me hurriedly turn it off. However, none of the handful of adults that were in the area at the time looked in my direction. People who had been walking about two to three meters ahead of us continued on without even giving us a glance. At the time, I felt a combination of surprise and uneasiness. (Asahi Shimbun, 9 August 2007)

Finally, sounding off the crime prevention buzzer may cause the perpetrator to become furious or panic and result in an elevated act of violence. An actual case took place in Nagasaki City in 2003 wherein a 12-year-old boy kidnapped a smaller 4-year-old child and killed him by pushing him off the roof of a parking lot. It was ruled by the police that there was "a high possibility that the perpetrator panicked after encountering an unexpected level of resistance, prompting him to throw the child off the roof on impulse." (Mainichi Newspaper, 13 July 2003)

Although crime prevention buzzers contain such limitations, one cannot, of course, refute the potential usefulness of these devices for self-defense. However, such devices are intended to be used at the moment the perpetrator strikes and, as such, their use from a child's perspective undoubtedly spells a crisis situation for that child. In short, crime prevention buzzers can be characterized as a last resort to prevent crime victimization. Therefore, it is necessary to search for a new method that would not rely solely on these devices.

\section{Identification of Fushinsya-the Suspicious Person}

This term fushinsya first appeared in the Risk Control Manual prepared by the Japanese Ministry of Education, Culture, Sports, Science and Technology in 2002, after multiple elementary school murders took place in 2001. Following the child kidnapping and murder cases in 2004, the Japanese National Police Agency established guidelines for child safety measures in 2005. It was within these guidelines that fushinsya was first defined. Fushinsya refers to 'a person who committed a crime' and 'a person with the potential to commit a crime.'

Because the definition of fushinsya could potentially include any suspicious individuals under a variety of contexts, it created some confusion and problems. First, children may inaccurately identify fushinsya based on their preconceived notion about "suspicious individuals." A survey conducted at an elementary school in Saitama Prefecture indicated that one out of two children cited sunglasses or a mask as the mark of a fushinsya (unpublished thesis by a Rissho University undergraduate student). This is inconsistent with the report of the Okayama Prefectural Police. For example, in 2006 the police report revealed that only $3 \%$ and $1 \%$ fushinsya wore sunglasses and a mask, respectively (Okayama Prefectural Police's website). 
Second, identification of fushinsya may unintentionally target individuals who are different from the mainstream population (e.g., foreigners, homeless individuals, and the mentally challenged). For example, the Tokyo Metropolitan Police Department distributed leaflets asking that Chinese persons be reported to the police department. Another shows that an elementary school in Niigata Prefecture sent out an email asking people not to go near parks due to the presence of homeless individuals there. A letter the author previously received from the parent of a mentally challenged child stated: "Alongside increasingly active crime prevention activities and patrols, my child is often incorrectly regarded as a fushinsya, causing us as parents distress."

Third, attempting to locate fushinsya may result in a sense of alienation and distrust within the community. As indicated in Yomiuri Shimbun (26 February 2005), a simple greeting, "hello," by a passerby triggered a child to panic and run away because she "did not know the person."

While both of these crime prevention programs designed to make the community safer for children have some practical limitations, perhaps one of the major drawbacks from the situational crime prevention perspective is the focus on the "person" rather than the "place." A more recent initiative of community safety maps may help to address this limitation.

\section{Community Safety Maps for Children and Their Implementation}

Community safety maps are maps that identify "hot spots" for criminal activities where children are more likely to become victims (see Figure 1). It is intended to serve as an educational program for elementary school children to shift their attention from "dangerous persons" to "dangerous places." These maps designed for children are different from maps distributed by the local police. The local crime maps are based on a two-dimensional widearea map, and duplicate a "bird's eye view" of the environment. In contrast, community safety maps are based on three-dimensional scenery, and duplicate a "bug's-eye view" of the environment. Local crime maps, when used in tandem with a geographical information system (GIS), are useful tools for achieving the proper allocation of police force. However, it is expected that community safety maps would be more realistic for children to identify dangerous places. This is because the word "place" in everyday life means neither its address nor coordinate, but scenery (Blades 1997).

Fig. 1 Child-driven community safety mapping. Source: Teaching Manual 2008 (Tokyo Metropolitan Government)

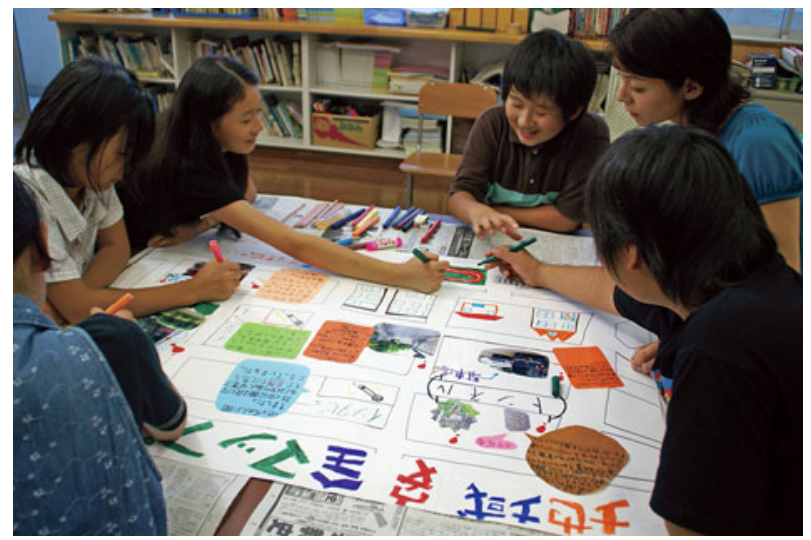


Four Steps towards the Implementation of Community Safety Maps

Several steps are involved in adopting the use of community safety maps, which are similar to the crime opportunity profiling conducted in the United Kingdom (Oxley et al. 2005).

The first step is chalk talk, through which teachers provide children with standards for gauging the probability that a crime will occur. The places preferred by criminals, the "hot spots," should be explained as 'places easy for anyone to enter' and 'places hard for everyone to be seen.' These two expressions represent the key phrases to be employed by children in detecting dangerous spots.

The second step is fieldwork that involves children forming groups and walking around their neighborhoods in search of 'places easy for anyone to enter' and 'places hard for everyone to be seen.' For example, a road with no guardrail erected represents a place easy for a criminal driving a car to enter the sidewalk and kidnap a child. Likewise, a road lined with poor-quality lampposts represents a place hard for children to be seen. A playground not enclosed with a mesh fence would be a place easy for anyone, including a criminal, to enter. Likewise, a park where playground equipment is hidden by dense vegetation would be considered a place hard for children to be seen. Locations such as meadows and rooftops that lack blind spots are easily considered safe upon first glance; however, since the line of sight of someone outside those locations cannot reach them, they would appropriately fall under 'places hard for everyone to be seen.'

Children are taught to inspect not only these kinds of physically dangerous locations but also those that are dangerous from a socio-psychological perspective. For example, areas found to exhibit signs of street-level disorder, such as graffiti, vandalism, fly-tipping, abandoned cars, and derelict buildings, are considered to be 'places easy for anyone to enter' due to their atmosphere of weakened access control. Moreover, due to the lack of neighborhood residents' interest in such locations, they would also fall under 'places hard for everyone to be seen.' Locations such as station plazas and shopping malls are easily considered safe upon first glance due to the presence of a large number of people. However, the more external stimuli there are, the harder it is for people to recognize the occurrence of an abnormal situation (this phenomenon is known as selective attention). As such, even if one does realize such a situation is occurring, greater numbers of individuals in an area makes it more difficult to initiate helping behavior (this is what is known as the bystander effect). Consequently, from a socio-psychological perspective, such locations fall under 'places hard for everyone to be seen.'

The purpose of fieldwork is to make children think whether or not these key phrases are applicable to the landscapes that they are viewing. Such efforts will enable children to determine whether or not a criminal prefers a certain location simply by viewing the scenery that accompanies it. Additionally, as part of their fieldwork, children are asked to interview neighborhood residents. Teachers leading these efforts should explain to the children that the purpose of such interviews is to gather information regarding dangerous places, but the true purpose of these interviews is to make children realize that the neighborhood residents are not fushinsya but are, in fact, people who help protect them from crime.

The third step in this process is to draw a map based on their fieldwork experience. This involves several steps. First, a thick felt pen should be used to draw "paths" and "landmarks" on a large-sized piece of paper. Next, children should be made to attach the landscape photographs that they took in the course of their fieldwork to the corresponding positions on the map. Lastly, children should write a comment on the map near the picture explaining why that location is dangerous (or safe). These maps should have clearly labeled 
places that are "hot spots" for crimes and places that are "defended" and "hardened" through environmental design.

The last step involves a presentation conducted in front of parents and neighborhood residents in which children report the results of their local investigation and appeal for actions to remedy deficiencies. This gives an opportunity for parents and neighborhood residents to show appreciation to children for their efforts in community crime prevention and allows the parents and residents to initiate their own efforts to improve the local community. All participating children are asked to speak at this presentation, even if it is only a single utterance. The purpose of this is to instill in children the ideas that 'No one gets excluded' and 'You did your part for the community.' Thus, lessons incorporating community safety maps are intended not only to enhance the risk prediction ability of children but also to open their eyes to the value of the democratic process and stimulate their motivation to contribute to society.

\section{Effects of Community Safety Maps}

Based on experiments in several schools throughout Japan and the available literature, there are several potential benefits associated with the community safety maps designed by and for children.

First, children are expected to acquire techniques for crime opportunity profiling. The risk prediction ability of children will increase, thereby reducing the probability that they encounter criminal and dangerous situations. Haramiishi and Iwai (2008) conducted an attitudinal survey of children both before and after they took part in the program implementation of community safety maps in an elementary school in Osaka. Their findings suggest that this program significantly improved elementary students' crime risk assessments. In another elementary school in Tokyo, after attending classes incorporating community safety maps, students no longer took short-cuts to school because of their increased awareness of dangerous places (Mainichi Newspapers, 26 March 2007). At another Tokyo elementary school, the number of children commuting to and from school alone decreased as a result of enhanced risk management awareness produced through lessons incorporating community safety maps (Asahi Shimbun, 1 December 2005).

The second effect is the likelihood of reduced juvenile delinquency. Building community safety maps requires teamwork. As a result, in the process of interacting with their fellow classmates, children are able to improve their communication ability and other social skills (Hira 2007). As stated above, the task of decorating the maps and presentations in which each and every child is to speak are intended to build a sense of camaraderie among children. Additionally, lessons incorporating community safety maps also take on the characteristics of "citizenship education" or "service-learning." Through engaging in locally based crime opportunity profiling, children elevate their level of interest in the local community. In addition, interviews with neighborhood residents also serve as a social device for forming bonds of trust between children and neighborhood residents. These activities are also likely to strengthen the bonds children have with their family and community, functioning as "protective factors" that help prevent juvenile delinquency (Hirschi 1969; Hawkins et al. 1999).

Finally, community safety maps may potentially contribute to crime reduction in local communities through increasing guardianship, effective place management, and community empowerment (Cohen and Felson 1979; Eck 2003; Kelling and Coles 1996). For example, in the City of Neyagawa in Osaka Prefecture, neighborhood residents improved the places 
with high child victimization risks after community safety maps were developed at a local elementary school (Yomiuri Shimbun, 16 November 2006). A report issued by the Japanese Ministry of Internal Affairs and Communications (2008: 216-217) stated that Takefuchi, an area located in the City of Yao in Osaka Prefecture, experienced a decrease in the number of street crimes after community safety maps were developed at an elementary school. According to this report, the number of street crimes decreased by $16 \%$ in Takefuchi even though the number of street crimes for the entire City of Yao increased by $7 \%$ when compared to the previous year.

Because of these documented and anticipated benefits of the community safety maps program, it was adopted in the 'Action Plan for the Realization of a Society Resistant to Crime' formulated by the Ministerial Meeting Concerning Measures Against Crime headed by the Japanese Prime Minister in 2008. Nevertheless, despite its official endorsement, the implementation of community safety maps has not been without obstacles.

\section{Structural and Cultural Obstacles for Implementing Community Safety Maps}

Since its initial conceptualization in 2002 , adoption of the community safety maps program has been slower than anticipated. For example, in Tokyo, where the strongest efforts are being made to achieve the widespread use of such maps, only $44 \%$ of elementary schools are conducting classes that incorporate community safety maps (Sankei Shimbun, 25 September 2009).

One obstacle seems to involve a structural factor. Before the conception of community safety maps, local crime maps were distributed by the police. These maps are designed based on crime data reported by the police and disseminated using a top-down approachfrom the police to the residents. In addition, these traditional maps were two-dimensional. While they may be useful for the police to keep track of crimes using GIS, there are limitations to their usefulness for children. Children cannot be expected to correctly interpret or remember these maps; nor can they be expected to walk around while referring to one. Rather, children walk around while looking at scenery (Blades 1997). Nevertheless, because of the similarity in names between these two maps, the adoption of the community safety maps program may meet institutional resistance from elementary schools.

The second obstacle may involve cultural preferences that undermine the critical learning components of the community safety maps. The majority of the Japanese populace continues to watch out for fushinsya. Consequently, even if elementary schools attempt to take advantage of maps for the purpose of anti-victimization, some parents and teachers may want to simply mark the spots on such maps where fushinsya appeared and distribute them among households. It is practically impossible for children to enhance their risk prediction ability simply by looking at these maps because this ability consists chiefly of deciphering scenery through "the eyes of a criminal."

\section{Conclusion}

From the situational crime prevention perspective, crime may be prevented if crime opportunity is reduced by increasing criminals' perceived effort (e.g., access control) and perceived risks (e.g., natural surveillance).

While there are fewer crime "hot spots" in Japan, there are still dangerous places and locations where crimes are more likely to occur. Community safety maps are intended to 
incorporate the key elements of this theoretical perspective by identifying "dangerous locations," hardening or empowering children (i.e., making children aware of these places and alter their behavior), and creating defensible space (i.e., promoting territoriality and surveillance of places). This is expected to yield positive results in crime prevention.

Because of the data limitations, this study represents a preliminary analysis of the community safety maps in Japan. Community safety maps, as argued here, have the potential to impact crimes against children. The process of developing community safety maps increases children's understanding and identification of dangerous places. The teamwork and unity that occurs throughout this process may help to strengthen guardianship for the children. The presentation of their findings to the community may also lead to structural changes in the environment to make places less dangerous. This study calls for additional research in the areas of program implementation and evaluation of community safety maps.

Open Access This article is distributed under the terms of the Creative Commons Attribution Noncommercial License which permits any noncommercial use, distribution, and reproduction in any medium, provided the original author(s) and source are credited.

\section{References}

Blades, M. (1997). Research paradigms and methodologies for investigating children's wayfinding. In: N. Foreman \& R. Gillett (Eds.), Handbook of spatial research paradigms and methodologies (Spatial cognition in the child and adult, vol. 1, pp. 103-129). Hove: Psychology.

Braga, A. A., \& Bond, B. J. (2008). Policing crime and disorder hot spots: a randomized controlled trial. Criminology, 46(3), 577-607.

Brantingham, P. J., \& Brantingham, P. L. (1984). Patterns in crime. New York: Macmillan.

Clarke, R. V. (1997). Introduction. In R. V. Clarke (Ed.), Situational crime prevention: successful case studies (2nd ed., pp. 2-43). Albany: Harrow and Heston.

Cohen, L. E., \& Felson, M. (1979). Social change and crime rate trends: a routine activity approach. American Sociological Review, 44, 588-608.

Cornish, D. B., \& Clarke, R. V. (1986). Introduction. In: D. B. Cornish \& R. V. Clarke (Eds.), The reasoning criminal: rational choice perspectives on offending (pp. 1-16). New York: Springer.

Cornish, D. B., \& Clarke, R. V. (2003). Opportunities, precipitators and criminal decisions: a reply to Wortley's critique of situational crime prevention. In: M. J. Smith \& D. B. Cornish (Eds.), Theory for practice in situational crime prevention, crime prevention studies (Vol. 16, pp. 41-96). Monsey: Criminal Justice Press.

Crawford, A. (1998). Crime prevention and community safety. London: Longman.

Crowe, T. D. (2000). Crime prevention through environmental design: applications of architectural design and space management concepts (2nd edn.). Boston, MA: National Crime Prevention Institute, Butterworth-Heinemann.

Eck, J. E. (2002). Preventing Crime at Places. In: L. W. Sherman, D. P. Farrington, B. C. Welsh, \& D. L. MacKenzie (Eds.), Evidence-based crime prevention (pp. 241-294). New York: Routledge.

Eck, J. E. (2003). Police problems: the complexity of problem theory, research and evaluation. In: J. Knutsson (Ed.), Problem-oriented policing: from innovation to mainstream, crime prevention studies (Vol. 15, pp. 79-113). Monsey: Criminal Justice Press.

Felson, M. (1998). Crime and everyday life (2nd ed.). Thousand Oaks: Pine Forge.

Felson, M. and Clarke, R. V. (1998). Opportunity makes the thief: practical theory for crime prevention. Police Research Series No. 98. London: Home Office.

Haramiishi, Y., \& Iwai, N. (2008). Shogakko ni okeru Kiken Kaihi Ryoku wo Minitsukeru tameno Anzen Kyoiku no Arikata [An ideal style of safety education to enhance the risk avoidance ability of children in elementary schools]. Syakai Anzen, 69, 17-28. 
Hawkins, J. D., Catalano, R. F., Kosterman, R., Abbott, R., \& Hill, K. G. (1999). Preventing adolescent health-risk behaviors by strengthening protection during childhood. Archives of Pediatrics \& Adolescent Medicine, 153(3), 226-234.

Hira, S. (2007). A preliminary analysis of effects of local safety mapping activity. Journal of Fukuyama University Psychological Services, 1, 35-42.

Hirschi, T. (1969). Causes of delinquency. Berkeley: University of California Press.

Japanese Cabinet Office. (2006). Kodomo no Bohan ni kansuru Tokubetsu Yoron Chosa [Special survey on crime prevention for children]. Tokyo: CAO.

Japanese Ministry of Internal Affairs and Communications. (2008). Chiiki Komyuniti Saisei [Regional Community Renaissance]. Tokyo: MIC.

Jeffery, C. (1971). Crime prevention through environmental design Beverly Hills: Sage.

Kelling, G., \& Coles, C. (1996). Fixing broken windows: restoring and reducing crime in our communities. New York: Touchstone.

Komiya, N. (1999). A cultural study of the low crime rate in Japan. British Journal of Criminology, 39(3), 369-390.

Newman, O. (1996). Creating defensible space. Washington, D.C.: U.S. Department of Housing and Urban Development, Office of Policy Development and Research.

Oxley, J., Reijnhoudt, P., van Soomeren, P., Beckford, C., Jongejan, A., \& Jager, J. (2005). Crime opportunity profiling of streets (COPS): a quick crime analysis-rapid implementation approach. Watford: BRE Bookshop for BRE Trust.

Sherman, L. W., Gartin, P. R., \& Buerger, M. E. (1989). Hot spots of predatory crime: routine activities and the criminology of place. Criminology, 27(1), 27-56.

Weisburd, D., \& Mazerolle, L. G. (2000). Crime and disorder in drug hot spots: implications for theory and practice in policing. Police Quarterly, 3(3), 331-349.

Wilson, J. Q., \& Kelling, G. (1982). Broken windows: the police and neighborhood safety (pp. 29-38). March: Atlantic Monthly. 